\title{
Modelling hyporheic exchange: From the boundary layer to the basin
}

\author{
$\underline{\text { M.J. Stewardson }}^{\text {a }}$, S.B. Grant ${ }^{\text {a,c,d }}$, I. Marusic ${ }^{\text {b }}$ \\ ${ }^{a}$ Department of Infrastructure Engineering \\ ${ }^{b}$ Department of Mechanical Engineering \\ Melbourne School of Engineering, The University of Melbourne, Victoria 3010, Australia \\ ${ }^{c}$ Department of Civil and Environmental Engineering \\ ${ }^{d}$ Department of Chemical Engineering and Materials Science \\ Henry Samueli School of Engineering, University of California, Irvine, CA 92697 \\ Email:mjstew@unimelb.edu.au
}

\begin{abstract}
Hydrological connections in streams occur longitudinally along the stream channel, laterally with the floodplain and vertically with the hyporheic zone. These connections are an important control on freshwater ecosystem processes at the basin-scale including nutrient cycling and retention; movements of organisms to complete life stages; and the provision of refugia during high and low flow periods. They also influence human and farm health by creating pathways for the sequestration and mobilization of microbial communities including human and animal pathogens. Methods are available to observe and model lateral and longitudinal hydrological connectivity at the basin-scale but this is not true for the vertical dimension. Understanding the strength of vertical hydrological connectivity across river basins is important for freshwater science and will lead to better catchment management for human and ecosystem health outcomes.
\end{abstract}

Hyporheic exchange is fundamental to vertical connectivity, transporting mass, energy, and momentum between the sediment and the water column. Recent work by the authors has led to the development of new resistance model of sediment-water interfacial flux at the patch scale (ca., 1 to $10 \mathrm{~m}$ ) including processes of hyporheic exchange. The model parameterizes patch-scale hyporheic exchange in terms of a mass transfer resistance coefficient $R$, and a scaling law for $R$ has been developed based on a meta-analysis of previously published hyporheic exchange experiments in recirculating laboratory flumes. For this study, we adapt this scaling law to natural stream channels in the Murray-Darling Basin using reach-averaged values of key hydraulic variables that are assumed to be fixed throughout the stream network or modeled using hydraulic geometry relations.

Our model of patch-scale hyporheic exchange predicts much more frequent exchange between the water column and the streambed in steeper upland streams. A molecule of water transported along a $100 \mathrm{~km}$ length of upland stream may journey into the streambed more than 1000 times. In contrast, the same molecule might only pass into the streambed once while being transported a similar distance in a lowland river. This suggests that any hyporheic processes influencing the character of the water column (through biogeochemical transformations or source-sink dynamics) will have a much stronger effect in steeper gradient rivers. The stronger hydrological connectivity between water column and hyporheic zone in steeper rivers is likely to promote buffering of solute and suspended contaminants delivered as a pulse from headwater catchments. This suggests an interesting interaction between vertical and longitudinal hydrological and biogeochemical connectivity at the basin-scale. Upland rivers may be characterized by strong vertical and weak longitudinal connectivity whereas the reverse may be true in lowland rivers.

Keywords: Hyporheic exchange, Ecohydraulics, Environmental flow, River networks, Resistance, Scale 


\section{INTRODUCTION}

Hydrological connections in streams occur longitudinally along the stream channel, laterally with the floodplain and vertically with the hyporheic zone. These connections are an important control on freshwater ecosystem processes at the basin-scale including nutrient cycling and retention; movements of organisms to complete life stages; and the provision of refugia during high and low flow periods. They also influence human and farm health by creating pathways for the sequestration and mobilization of microbial communities including human and animal pathogens. Hyporheic exchange is fundamental to vertical connectivity, transporting mass and energy between the sediment and the water column. This exchange produces steep biogeochemical gradients in the hyporheic zone that support a unique community of benthic and interstitial microorganisms (Brunke and Gonser 1997), cycle carbon, energy, and nutrients (Malard et al. 2002; Pinay et al. 2009; Hinkle et al. 2001), and decontaminate the overlying water column (Gandy et al. 2007). The hyporheic zone also regulates stream temperature and sediment budgets, and serves as a spawning ground for fish (Greig et al. 2007), refuge for benthic organisms (Dole-Olivier et al. 1997, Wood et al 2010)), and a rooting zone for aquatic plants (Buss et al., 2009).

Methods are available to observe and model lateral and longitudinal hydrological connectivity at the basinscale but this is not true for vertical connectivity (Bencala et al. 2011). There is progress in understanding patterns of hyporheic exchange at individual bed particles (Reidenbach et al., 2010), across geomorphic units such as riffles and pools (Tonina and Buffington, 2007) and along short river reaches (Stonedahl et al., 2010). However, variation in hyporheic exchange at basin-scales is poorly understood and, until recently, there has been no model available to predict hyporheic exchange using data available at the basin-scale. Our objective in this paper is to map patch-scale hyporheic exchange (ca., 1 to $10 \mathrm{~m}$ ) at the basin scale using recent modeling developments by the authors.

Hyporheic exchange has been modeled as a diffusive process using Fick's first law,

$J_{y}=-\left.D_{\text {eff }} \frac{\partial C_{s}}{\partial y}\right|_{y=0}$

Here, $J_{y}$ represents the flux of tracer on the sediment side of the sediment-water interface, $D_{\text {eff }}$ is an effective diffusion coefficient, $C_{s}$ is the concentration of tracer in the sediment interstices, and $y$ is a spatial coordinate oriented normal to, and directed into, the sediment. Whilst diffusive processes will contribute to exchange across a sediment-water interface (Grant and Marusic, 2011), advective processes will most likely dominate exchange in most natural stream channels. Hyporheic exchange occurs over a hierarchy of spatial scales, from single grains to entire catchments (Buss et al., 2009; Tonina and Buffington, 2007; Stonedahl et al., 2010; Bencala et al., 2011). At the local or "patch" scale (ca., 1 to $10 \mathrm{~m}$ ), hyporheic exchange is produced by a number of mechanisms, including: (1) time averaged pressure gradients associated with geomorphic features such as riffles and pools (Tonina and Buffington, 2007) and the detachment and reattachment of the turbulent boundary layer over roughness elements on the sediment bed such as ripples, dunes, and cobbles (Elliot and Brooks, 1997a,b; Reidenbach et al., 2010); (2) entrapment and release of pore water as a result of mobilization and deposition of boundary sediments caused by, for example, the downstream migration of dunes and ripples (Elliot and Brooks, 1997a; Elliot, 1991), and (3) fluctuations in the pressure distribution caused by eddying motions in the stream that operate over a large range of spatial and temporal scales (Fries, 2007; Packman et al., 2004; Higashino et al., 2009, Boano et al., 2011). Variations in sediment permeability affects the rate at which water moves in and out of the sediment bed in response to both steady and fluctuating pressure distributions (Buss et al., 2009; Worman et al., 2002).

Representing advective hyporheic exchange as a diffusive process (i.e. Eq. 1) presents some problems (Grant et al. under review). In particular, field estimation of effective diffusion coefficients, in order to implement eq. 1, requires measurements of concentration gradients on the sediment side of the interface, something that is rarely available. It is also difficult to convert $D_{\text {eff }}$ into a resistance or mass transfer coefficient, because there is no obvious choice for an appropriate diffusional length-scale given the many different processes that are represented operationally by $D_{\text {eff. }}$. Sediment-water exchange can be modeled using the concept of "resistance" (Grant and Marusic, 2011) using

$J_{y}=\frac{-\Delta C}{R}$

where $\Delta C$ is concentration of the solute in the stream water column less the concentration in the hyporheic zone. The mass transfer resistance $(R)$ has units of inverse velocity. Resistance models for mass transfer at the sediment-water interface are subject to a number of assumptions; most notably that mass flux $J_{y}$ is constant. This imposes the following three conditions within the region, or "control volume", across which 
mass is transferred at the sediment-water interface: (1) steady-state; (2) no sources or sinks; and (3) horizontally uniform. Theoretical and empirical studies suggest that mass transfer resistance due to transport through the hydrodynamically controlled portion of the water column or at roughness elements at the sediment-water interface [so-called "streamside-exchange", Grant and Marusic (2011)] can be calculated simply from the shear velocity and Schmidt number. More recently, the authors have fitted a scaling law for resistivity using results from the same 50 recirculating flume tracer studies included in the meta-analysis of $D_{\text {eff }}$ by O'Conner and Harvey (2008). This scaling law is provided here as a preliminary result:

$u_{*} R=3.08\left(\frac{u \sqrt{\kappa}}{v}\right)^{-1.24}\left(\frac{u}{u_{*}}\right)^{-0.51} S c^{0.84}$

where, $v$ is the kinematic viscosity, $u$ is the mean flow velocity in the water column, $u *$ is the bed shear velocity, $\kappa$ is the sediment permeability, and $S c$ is the Schmidt number $\left(S c=v / D_{m}\right.$ where $D_{m}$ is the molecular diffusion coefficient). Our purpose in this study is to use equation 3 as a basis for mapping regional scale variations in patch-scale hyporheic exchange through the Murray-Darling Basin. There are a number of challenges and assumptions required in upscaling from laboratory flume experiments to an entire river basin.

\section{MAPPING PATCH-SCALE HYPORHEIC EXCHANGE ACROSS A BASIN}

We use the empirical model for $R$ (Eq. 3) to prepare basin maps of patch-scale hyporheic exchange. To do this, we rewrite eq. 3 using dimensional variables, making the simplification that the controlling hydraulic variables $u, u_{*}$ and $\kappa$ can be replaced by reach-averaged equivalents of velocity $(U)$, shear stress $\left(U_{*}\right)$ and intrinsic permeability of bed sediments (K). To avoid confusion we use $\bar{R}$ to denote an average mass transfer resistance through a stream reach,

$\bar{R}=3.08 v^{2.08} D_{m}{ }^{-0.84} U^{-0.51} U_{*}^{-1.73} \mathrm{~K}^{-0.62}$

For this basin-scale analysis, we evaluate hyporheic exchange as a volumetric flux rate (into the sediment bed) per unit length of channel $\left(J_{y}^{\prime}\right)$, where

$J_{y}^{\prime}=\frac{W}{\bar{R}}$

and $W$ is the reach-mean channel width at the water surface level.

In order to apply this model at the basin-scale we need basin-wide data on properties of flow in the river channel $\left(U, U_{*}\right.$, and $\left.W\right)$ and streambed permeability $(\mathrm{K})$. For simplicity, we neglect variations in the properties of water and its constituents $(\mathrm{V}$ and $S c)$.

We model $U, U_{*}$, and $W$ using at-a-station hydraulic geometry relations (Leopold and Maddock, 1953) widely applied in fluvial geomorphology. Typically, channel water surface width $(W)$ and mean water depth $(D)$ are given as power laws of discharge $(Q)$ :

$W=a Q^{b}$
$D=c Q^{d}$

The coefficient ( $a$ and $c$ ) and exponents $(b$ and $d$ ) can be estimated by log-log regression using measured width and depth at two or more discharges. $W$ and $D$ usually denote the water surface width and mean water depth for an individual channel cross-section. However, Stewardson (2005) proposed that these power laws could also be used for reach-mean values of water surface width and depth. If the geometric mean of width and depth is used (Harman et al. 2008), the mean cross-sectional velocity along the reach is given by.

$U=\frac{Q}{W D}$

For reach shear velocity we use

$U_{*}=\sqrt{g D S}$

where $g$ is gravitation acceleration. By combining Eqs. 4 to 9 we can estimate vertical exchange as

$J_{y}^{\prime}=0.325 \frac{D m^{0.84} \mathrm{~K}^{0.62} g^{0.87} S^{0.87} a^{0.49} c^{0.36} Q^{[0.51+0.49 b+0.355 d]}}{v^{2.08}}$ 
Stewardson (2005) estimated reach hydraulic geometry exponents and coefficients for 17 river reaches across a broad range of stream sizes and gradients, mostly in southeastern Australia. Average exponents were $b=$ 0.11 and $d=0.28$ and coefficients $(a$ and $c$ ) were estimated by empirical relations with mean (i.e. timeaveraged) discharge for the site $(\bar{Q})$ and stream gradient $(S)$,

$$
\begin{aligned}
& a=6.21 \bar{Q}^{0.45} \\
& c=0.082 S^{-0.310}
\end{aligned}
$$

Using these mean exponents and Eq. 11 and 12 in Eq. 10 we obtain

$$
J_{y}^{\prime}=2.36 \frac{D m^{0.84} \mathrm{~K}^{0.62} \bar{Q}^{0.22} S^{0.76} Q^{0.67}}{v^{2.08}}
$$

Interestingly, exponents for discharge and stream gradient are similar suggesting the importance of stream power ( $\rho g Q S$ where $\rho$ is water density) in controlling patterns of patch-scale hyporheic exchange.

In order to explore the relative importance of vertical exchange with the hyporheic zone, we define a stream reach length $(L)$ for which the flux of a solute transported by advection along the stream channel is equal to the vertical exchange of the solute from the water column to the streambed (assuming the streambed solute concentration is zero). This length is given by

$L=\frac{Q}{J_{y}^{\prime}}$

The length scale, $L$, can be interpreted as the mean travel distance between excursions of individual water molecules into the streambed. Substituting 13 in 14

$$
L=\frac{0.42 v^{2.04} Q^{0.33}}{D m^{0.84} \mathrm{~K}^{0.62} \bar{Q}^{0.22} S^{0.76}}
$$

The permeability of boundary sediments is closely related to the hydraulic conductivity $k(\kappa=k v / g)$ and varies with flow direction within the sediments, position within the channel, depth within the bed sediments and through time as result of sediment erosion and scour and possibly gas content, bioturbaton and biofilms (Landon et al. 2001; Genereux et al. 2008; Chen 2010). Importantly, it is fine sediment sizes within the graded bed sediments that are the dominant control. There are several empirical models relating hydraulic conductivity to an effective grain size, usually defined as the $10^{\text {th }}$ or $20^{\text {th }}$ percentile grain size by weight (Song et al. 2008). However, these empirical relations are of limited value in basin-scale modelling because of their poor performance when compared to field permeameter measurements (Song et al. 2008; Vienken and Dietrich 2011) and limited data on variability in these grain size parameters.

Table 1: Reported values of vertical hydraulic conductivity $\left(k_{v}\right)$ at the streambed surface measured using permeameter tests

\begin{tabular}{|l|c|c|c|c|c|}
\hline \multicolumn{1}{|c|}{ Study } & $\begin{array}{c}\text { Number } \\
\text { of sites }\end{array}$ & $\begin{array}{c}\text { Mean } \\
\text { number of } \\
\text { cores per } \\
\text { site }\end{array}$ & $\begin{array}{c}\text { Sediment } \\
\text { depth range } \\
(\mathrm{m})\end{array}$ & $\begin{array}{c}\text { Mean } \\
k_{v} \\
(\mathrm{~m} / \text { day })\end{array}$ & $\begin{array}{c}\text { Range in } \\
k_{v} \\
(\mathrm{~m} / \text { day })\end{array}$ \\
\hline Chen (2010) & 9 & 1 & $0-1.5$ & 38 & $10-64$ \\
\hline Cheng et al. (2011) & 18 & 30 & $0-0.5$ & 29 & $17-48$ \\
\hline Genereux et al. (2008) & $7^{*}$ & 46 & $0-0.36$ & 7.1 & $1.4-12$ \\
\hline Song et al. (2008) & 7 & 8 & $0-0.6$ & 28 & $11-57$ \\
\hline
\end{tabular}

* these are repeat samples for the same site over a year

Recent studies provide vertical hydraulic conductivity measured using field permeameter tests in surficial streambed sediments of between $1.4 \mathrm{~m} /$ day and $64 \mathrm{~m} /$ day (Table 1). Song et al. (2008) includes sites over a particularly broad range of stream sizes (along the same river) but the range of $k_{y}$ values is relatively small $(11 \mathrm{~m} /$ day to $57 \mathrm{~m} /$ day). This contrasts to typical variations in stream gradient and discharge over several orders of magnitude. This is unexpected given the broad range of dominant sediment sizes in streams varying from cobbles to silts and clays in the downstream direction. It is not inconceivable that course sediments, which might be expected to have a high permeability, are clogged with finer sediments transported into the 
interstices as a consequence of high rates of hyporheic exchange leading to reduced permeability and lower exchange rates. This negative feedback mechanism may result in a relatively narrow range of surfical streambed permeabilities in streams where fine sediments are transported in the water column and there is sufficient time with a stable bed to allow accumulation of these fines in the streambed. Regardless of the mechanism, we will assume a uniform reach permeability $(\mathrm{K})$ for our purpose of modelling hyporheic exchange throughout a river basin.

\section{PATCH-SCALE HYPORHEIC EXCHANGE IN THE MURRAY-DARLING BASIN}

We apply the resistance model of hyporheic exchange (Eq. 13) to the Murray-Darling Basin. Results are expressed as $J$ ' (with units of $\mathrm{m}^{2} / \mathrm{s}$ ) and $L$ (Eq. 15) to represent basin-wide patterns in patch-scale hyporheic exchange rates. The model is applied at mean flow conditions for every segment in the DEM-derived streamlines of the Australian Hydrological Geospatial Fabric available from Geoscience Australia. Mean flow and valley gradient corresponding to every segment in this digital stream network are available in an associated database (Unpublished data supplied by Janet Stein, CRES ANU). Valley gradient is divided by 1.3 to adjust for typical river sinuosity in estimating river gradient (M Stewardson, unpubl. data). The mean flow corresponds to a pre-development state. Equations 13 and 15 predict that reductions in mean flow with water resource development will reduce both $J_{\mathrm{y}}$ (with units of $\mathrm{m}^{2} / \mathrm{s}$ ) and $L$ in the many larger rivers across the basin subject to water diversions.

We assume a constant water temperature of $20^{\circ} \mathrm{C}$ throughout the basin and use the molecular diffusivity of $\mathrm{NaCl}$. Under these conditions $\mathrm{v}=1.004 \times 10^{-6} \mathrm{~m}^{2} / \mathrm{s}$ and $D_{m}=1.5 \times 10^{-9} \mathrm{~m}^{2} / \mathrm{s}$. We use the mean $k_{y}$ value measured by Song et al. (2008) which is similar to mean values in other studies (Table 1) and corresponds to an intrinsic permeability of $3.3 \times 10^{-11} \mathrm{~m}^{2}$ (assuming $k_{y}$ was measured at $20^{\circ} \mathrm{C}$ ). Substituting these values into equations 13 and 15 we get

$J_{y}^{\prime}=0.091 \bar{Q}^{0.87} S^{0.76}$

$L=11 \bar{Q}^{0.11} S^{-0.76}$

Figure 1 maps these two measures of patch-scale hyporheic exchange in the Murray-Darling Basin. For clarity, only streams with a mean discharge greater than $0.016 \mathrm{~m}^{3} / \mathrm{s}$ have been included. The results show a consistent downstream trend in $L$ with lower values in the upper catchment. No such trend is apparent in $J^{\text {' }}$ although the southern basin generally has higher values than the northern basin.

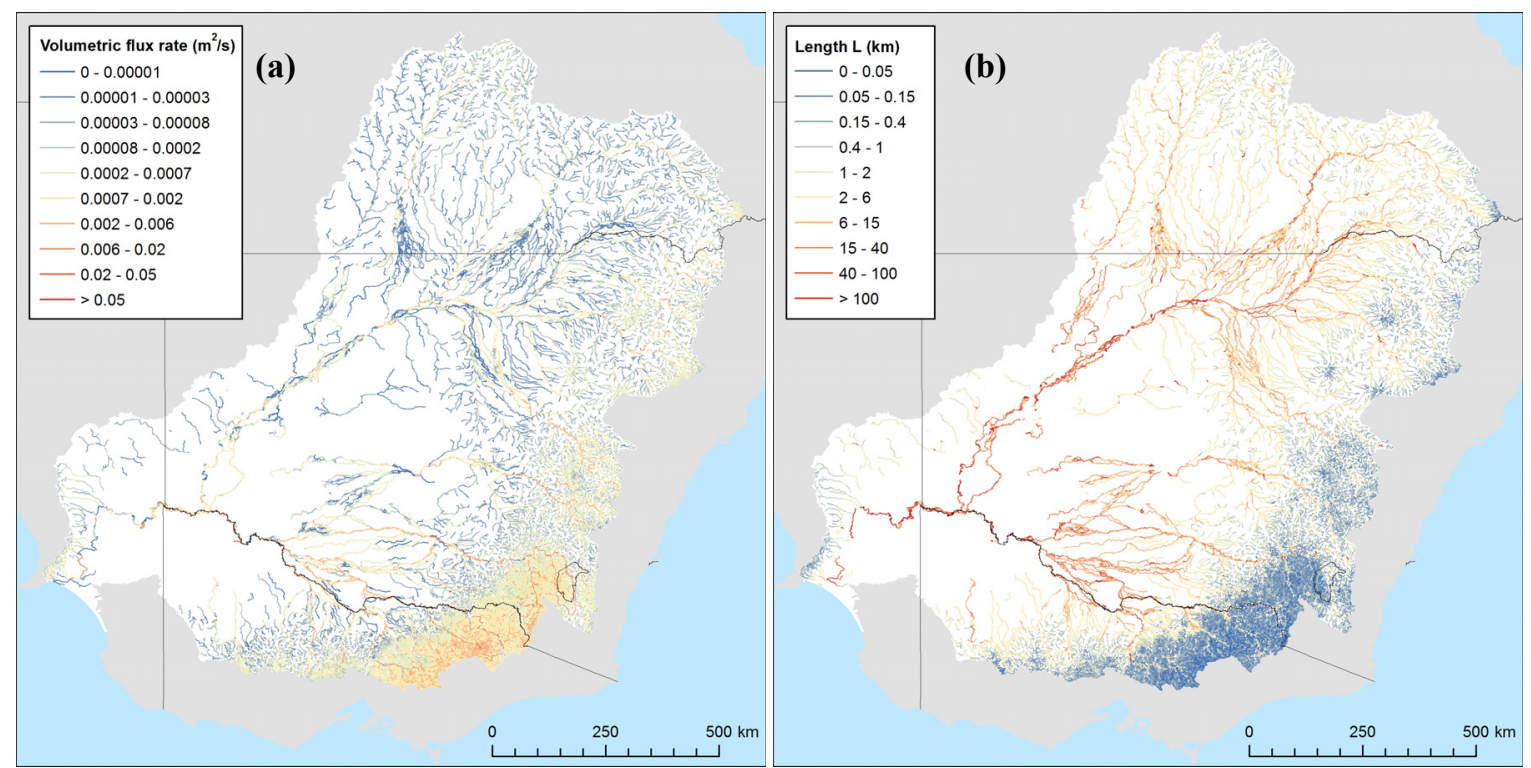

Figure 1: Distribution of patch-scale hyporheic exchange rates in the Murray-Darling Basin mapped as: (a) volumetric rate of exchange per unit length of channel; and (b) the mean reach length between excursions into the streambed (inset map shows location of the Murray-Darling basin in Australia).

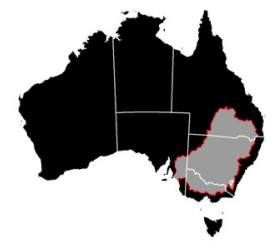




\section{DISCUSSION AND CONCLUSIONS}

There are some important limitations of the basin-scale model used in this paper. Firstly the model only represents patch-scale hyporheic exchange processes. It does not represent hyporheic "pumping" due to steady pressure gradients at pools and riffles, around meander bends or larger scale variations in river gradient. Nor does it represent any groundwater interactions. In this way, the model is a minimum estimate of hyporheic flux and we expect model developments, incorporating these larger-scale processes, to predict greater hyporheic flux estimates.

Depth-averaged velocity, shear velocity and bed permeability will vary within a river reach with likely strong covariance of all three variables. For example, deeper parts of a channel cross-section can have higher flow velocity, shear velocity and permeability (Stewardson and McMahon 2002 and Genereux et al. 2008). We have neglected this covariance in applying reach-mean values in equation 4 . The spatial arrangement of the controlling hydraulic variables and in particular covariance is worthy of closer examination.

Variation in $W, D$ and $U$ through the basin is represented using an empirical model based on observations at a small sample of stream reaches used by Stewardson (2005). Streambed permeability is approximated as uniform. A better understanding of variations in these controlling variables through the catchment and their dynamics will improve basin-scale analysis of hyporheic exchange in the future.

Our model of patch-scale hyporheic exchange predicts much more frequent exchange between the water column and the streambed in steeper upland streams. A molecule of water transported along a $100 \mathrm{~km}$ length of upland stream may journey into the streambed more than 1000 times. In contrast, the same molecule might only pass into the streambed once while being transported a similar distance in a lowland river. This suggests that any hyporeheic processes that influence the character of the water column (e.g. through biogeochemical transformations or source-sink dynamics) will have a much stronger effect in steeper gradient rivers. The stronger hydrological connectivity between the water column and hyporehic zone in steeper rivers is likely to promote buffering of solute and suspended contaminants delivered as a pulse from headwater catchments. This suggests an interesting interaction between vertical and longitudinal hydrological and biogeochemical connectivity at the basin-scale. Upland rivers may be characterized by strong vertical and weak longitudinal connectivity whereas the reverse may be true in lowland rivers.

\section{ACKNOWLEDGMENTS}

This research was supported by the University of Melbourne School of Engineering Iconic Research Project; an Australian Research Council Linkage Project (LP100200170 (to MS); a 2011 UCI Henry Samueli School of Engineering Research Ignition Fund (to SBG); and a National Science Foundation Award \# 0724806 (to SBG). Figure 1 was drawn by Dr. Stephen Wealands, The University of Melbourne.

\section{REFERENCES}

Bencala, K.E., Gooseff, M.N., and Kimball, B.A. (2011) Rethinking hyporheic flow and transient storage to advance understanding of stream-catchment connections, Water Resoures Res., 47, W00H03, doi:10.1029/2010WR010066.

Boano, F., Revelli, R., and Ridolfi L. (2011) Water and solute exchange through flat streambeds induced by large turbulent eddies, J. Hydrology 402, 290-296.

Brunke M and Gosner T. (1997) The ecological significance of exchange processes between rivers and groundwater, Freshwater Biology 73(1): 1-33

Buss, S., et al. (2009), The Hyporheic Handbook: a handbook on the groundwater-surface water interface and hyporheic zone for environment managers., Integrated Catchment Science Programme, Science report SC040070, Environment Agency, Bristol, U.K.

Chen, X. (2010) Depth-dependent hydraulic conductivity distribution patterns of a streambed. Hydrological Processes 25(2):278-287.

Cheng, C., Song, J. Chen, X. and Wang, D. (2011) Statistical Distribution of Streambed Vertical Hydraulic Conductivity along the Platte River, Nebraska. Water Resources Management 25:265-285

Dole-Olivier MJ, Marmonier, P. and Beffy J.L. (1997) Response of invertebrates to lotic disturbance: Is the hyporheic zone a patchy refugium? Freshwater Biology 37(2):257-276

Elliot, A.H. (1991), Transfer of solutes into and out of streambeds, PhD thesis, Department of Environmental Engineering Science, California Institute of Technology, Pasadena, California.

Elliott, A.H. and Brooks, N.H. (1997a) Transfer of nonsorbing solutes to a streambed with bedforms: Theory Water Resources Res. 33(1), 123-136. 
Elliott, A.H. and Brooks N.H. (1997b) Transfer of nonsorbing solutes to a streambed with bed forms: Laboratory experiments, Water Resources Res. 33(1), 137-151.

Fries, J.S. (2007) Predicting interfacial diffusion coefficients for fluxes across the sediment-water interface, ASCE J. Hydraulic Engineering, 133(3):267-272, doi: 10.1061/(ASCE)0733-9429(2007)133:3(267).

Gandy, CJ, Smith, J.W.N. and Jarvis, A.P. (2007) Attenuation of mining-derived pollutants in the hyporheic zone: A review. Science of The Total Environment. 373: 435-446.

Genereux, D.P., Leahy, S., Mitasova, H., Kennedy, C.D. and Corbett, D.R.. 2008. Spatial and temporal variability of streambed hydraulic conductivity in West Bear creek, North Carolina, USA. Journal of Hydrology 358: 332-353.

Grant, S.B. and Marusic I. (2011) Crossing turbulent boundaries: Interfacial flux in environmental flows, Environ. Sci. Technol, in revision.

Grant, S.B., Stewardson, M.J., and Murasic I. (under review) Making "Coherent" the Effective Diffusion Coefficient for Hyporheic Exchange. Water Resources Research.

Greig, S.M., Sear, D.A. and Carling, P.A. (2007) A review of factors influencing the availability of dissolved oxygen to incubating salmonid embryos. Hydrological Processes 21(3):323-334

Harman, C., Stewardson, M., and DeRose, R. (2008) Variability and Incertitude in Reach Bankfull Hydraulic Geometry. Journal of Hydrology 351: 13- 25

Higashino, M., Clark, J.J. and Stefan, H.G. (2009) Pore water flow due to near-bed turbulence and associated solute transfer in a stream or lake sediment bed. Water Resources Res. 45, doi:10.1029/2008WR007374.

Hinkle, S.R., Duff, J.H., Triska, F.J., Laenen, A., Gates, E.G, Bencala, K.E. Wentz D.A. and Silva S.R. (2001) Linking hyporheic flow and nitrogen cycling near the Willamette River - a large river in Oregon, USA. Journal of Hydrology 244(3-4):157-180

Landon, M.K., Rus, D.L. and Harvey, F.E. (2001) Comparison of instream methods for measuring hydraulic conductivity in sandy streambeds. Ground Water 39(6):870-885

Leopold, L.B., Maddock, T., 1953. The hydraulic geometry of stream channels and some physiographic implications. United States Geological Survey, 1-57.

Malard, F, K. Tockner, M-J Dole-Olivier, and J.V. Ward (2002) A landscape perspective of surfacesubsurface hydrological exchanges in river corridors. Freshwater Biology 47(4):621-640

O’Connor, B.L. and Harvey J.W. (2008) Scaling hyporheic exchange and its influence on biogeochemical reactions in aquatic ecosystems. Water Resources Res. 44, doi:10.1029/2008WR007160.

Packman, A.I., Salehin, M. and Zaramella M. (2004) Hyporheic exchange with gravel beds: basic hydrodynamic interactions and bedform-induced advective flows. ASCE J. Hydraulic Eng. 130(7): 647656.

Pinay, G., O'Keefe, T.C., Edwards, R.T., and Naiman R.J. (2009). Nitrate removal in the hyporheic zone of a salmon river in Alaska. River Research and Applications. 25: 367-375.

Reidenbach, A., Limm, M., Hondzo, M. and Stacey M.T. (2010) Effects of bed roughness on boundary layer mixing and mass flux across the sediment-water interface. Water Resour. Res., 46, doi:10.1029/2009WR008248.

Song, J., Chen, X.H., Cheng, C., Wang, D., Lackey, S. and Xu, Z. (2009) Feasibility of grain-size analysis methods for determination of vertical hydraulic conductivity of streambeds. Journal of Hydrology 375(34): $428-437$

Stewardson, M.J. (2005) Hydraulic geometry of stream reaches. Journal of Hydrology 306: 97-111

Stewardson, M.J. and McMahon, T.A. (2002) A stochastic model of hydraulic variations in stream reaches, Water Resources Research 38(1): Art Num 1007

Stonedahl, S.H., Harvey, J.W., Worman, A., Salehin, M. and Packman, A.I. (2010) A multiscale model for integrating hyporheic exchange from ripples to meanders. Water Resources Res. 46, doi:10.1029/2009WR008865.

Tonina, D. and Buffington J.M. (2007) Hyporheic exchange in gravel bed rivers with pool-riffle morphology: laboratory experiments and three-dimensional modeling. Water Resour. Research 43, doi: 10.1029/2005WR004328.

Vienken, T. and Dietrich, P. (2011) Field evaluation of methods for determining hydraulic conductivity from grain size data. Journal of Hydrology 400:58-71

Wood, P.J, Boulton, A.J., Little, S., and Stubbington, S. (2010) Is the hyporheic zone a refugium for aquatic macroinvertebrates during severe low flow conditions? Fundamentals of Applied Limnology 176(4):377390

Worman, A., Packman, A.I., Johansson, H. and Jonsson, K. (2002) Effect of flow-induced exchange in hyporheic zones on longitudinal transport of solutes in streams and rivers. Water Resources Res. 38(1), doi: 10.1029/2001WR000769. 